\title{
Student-Managed Commodity Fund-A New Frontier in Experiential Learning
}

\author{
Olga Isengildina Massa ${ }^{\star}$ (1) and A. Ford Ramsey (D) \\ Department of Agricultural and Applied Economics, Virginia Tech, Blacksburg, Virginia, USA \\ ${ }^{*}$ Corresponding author. Email: oimassa@vt.edu
}

\begin{abstract}
This study provides a road map for creating and operating a student-managed investment fund (SMIF) as an experiential learning opportunity in commodity market analysis. We describe the reasons for implementing a SMIF and the benefits it offers relative to traditional simulation approaches. We outline the necessary steps for starting a SMIF and explain its organizational structure. We discuss a SMIF's operation and main activities, which include recruitment, training, trading, and interaction with the client and alumni. The implications of participating in a SMIF are reviewed within a cost-benefit framework.
\end{abstract}

Keywords: Commodity investing; commodity marketing education; experiential learning; student-managed investment fund JEL Classifications: A22; A23; Q02; G11

The commodity markets were initially an immense challenge to understand, but that challenge enabled me to unlock analytical skills that I have never applied in classes for the $15+$ years I have been in school.

—Suddy Sriram, COINS alumni

\section{Background}

Understanding the dynamics and risks of commodity markets is an important skill for graduates in agricultural economics. This skill commands a premium in the workplace because of the extent of the commodity marketing and risk management activities of both family farms and agribusiness firms. A survey of grain merchandisers by Kliethermes, Parcell, and Franken (2011) showed that the ability to understand futures markets and basis was considered crucial knowledge for graduates. Expertise in commodity markets is also important for banks and other investment organizations that hold commodities as part of their portfolios. Over the past decade, commodity investments have become increasingly popular within the fund management industry because of their potential to enhance portfolio performance (Bessler and Wolf, 2015).

Most of the departments of agricultural economics across universities in the United States offer a course on commodity marketing and futures and options. Furthermore, many departments provide experiential learning opportunities for students to develop proficiency in these skills. The most common form of experiential learning in commodity markets is the market simulation (Koontz et al., 1995; Lawrence, 1990). Simulated portfolios are used to provide students with an opportunity to examine market dynamics, understand financial risk, and gain experience with the ins and outs of trading. The use of such games can provide an experiential learning tool in the

(c) The Author(s) 2019. This is an Open Access article, distributed under the terms of the Creative Commons Attribution licence (http:// creativecommons.org/licenses/by/4.0/), which permits unrestricted re-use, distribution, and reproduction in any medium, provided the original work is properly cited. 
agricultural economics curriculum (Koontz et al., 1995). However, in an era when employers are demanding graduates who are fully competent, a single semester course may not provide adequate training or experience. Paper portfolios also make it difficult for students to view their investment decisions as more than an exercise (Lawrence, 1990).

Another approach, the commodity trading pool, described by Tierney (1989) and Parcell and Franken (2009), has been implemented at Kansas State University and the University of Missouri. In this application, students buy shares in the trading pool when they register for the accompanying course. However, total funds in the pool are limited by enrollment and do not typically roll over from semester to semester. If invested in futures and options contracts, investment choices may be limited to minicontracts because of underlying contract size. Although the trading pool has the advantage of investing real money in which students have a stake and may align closely with the practices of small hedgers, the size of the pool limits its ability to mimic the practices of larger investment organizations.

The goal of this article is to describe the implementation of a student-managed commodity investment fund as an effective tool for mastering knowledge and skills related to commodity markets. Student-managed investment funds (SMIFs) are real monetary portfolios managed by university students who treat the portfolio as a financial manager would treat the funds of his or her clients (Gradisher et al., 2016; Lawrence, 1994). SMIFs have been recognized as premier tools for investment education among finance departments nationally and around the world (Holzhauer et al., 2019). Survey data from Lawrence (2008) and Rise Vision (http:// universityfinancelab.com/finance-lab-stats) indicate that about $10 \%$ of U.S. universities have a SMIF. Modern SMIFs share information and ideas through the Student Managed Investment Fund Consortium (https://www.indstate.edu/business/SMIFC) and during professional meetings (Holzhauer et al., 2019).

Although SMIFs traditionally invest in equities or bonds, ${ }^{1}$ similar benefits can be realized in commodity investing in the context of agricultural economics. Our program was spearheaded by agricultural economics alumni who saw a lack of human capital with experience in investing in commodities within financial institutions and a need to provide students with experiential learning opportunities by allowing them to analyze, track, and trade within commodity markets. Even though investing in commodity markets is very different from investing in stocks in both approach and investment horizon, our experience demonstrates that a SMIF provides a great model for incorporating experiential learning in commodity price analysis programs across the country.

We describe the organization and implementation of the commodity-focused SMIF operating at Virginia Tech (VT) since 2012. As far as we are aware, this is the only program of its kind in the United States. Our article is organized as follows: we first outline the differences between a SMIF and traditional experiential learning approaches used in commodity marketing education and discuss why a SMIF may be a preferred approach. This is followed by a description of the organizational structure of the SMIF and the roles of its participants. The next section describes the SMIF activities and operations. We conclude by discussing the impacts of the SMIF on students and learning outcomes, as well as the costs of implementing such a program. In response to multiple inquiries from colleagues at other institutions, we hope that this blueprint will allow commodity SMIF programs to be replicated on college campuses nationwide.

\section{Why implement a SMIF?}

The SMIF provides an experiential framework for students to learn the fundamentals of commodity markets without some of the limitations of simulated portfolios or trading pools, or the limited

\footnotetext{
${ }^{1}$ A survey by Peng, Dukes, and Bremer (2009) found that $69 \%$ of surveyed funds invested upward of $90 \%$ of their capital in equities.
} 
time frame associated with a single university course. The main difference between a commodity SMIF and traditional simulation-based approaches (Koontz et al., 1995; Lawrence, 1990, 1994) is that it provides a real monetary fund that is invested through a real brokerage firm (E-Trade in our case). The fund is allocated across real financial instruments (exchange-traded funds [ETFs] and exchange-traded notes [ETNs]). Exposure to real-life accounts teaches students how to deal with challenging situations like obtaining and analyzing real-time data, handling unusual events when financial instruments are delisted and others are introduced in their place, experiencing low volume and the implications of thin markets on the costs of trading, facing limitations in terms of the types of orders that can be handled by a broker, and more. Most of these situations are likely not available in a simulation environment. Investing real money on behalf of the university gives the students an added sense of responsibility and ensures the thoroughness of analysis accompanying each trade.

The main difference between a SMIF and a commodity trading pool (Parcell and Franken, 2009; Tierney, 1989) is the length of the investment horizon (more than one semester for a SMIF), the size of the investment portfolio (typically much larger for a SMIF), and client (VT Foundation) requirements/constraints (not relevant for trading pools). Although the longer investment horizon and a larger portfolio provide added flexibility for a SMIF, client requirements may be very demanding and restricting. They force students to learn how to operate within the guidelines established by the client and provide reporting for the client regarding the fund's performance. This important feature closely mimics real-life money management company conditions but may not be required in trading pool approaches. The SMIF requirement to calculate and report performance measures on the quarterly, semiannual, and annual basis adds another layer of responsibility and accountability for participating students. Overall, SMIFs provide a more holistic and realistic investment experience to participating students.

Furthermore, Holzhauer et al. (2019, p. 2) argue that "these programs allow students to move from 'theoretical' to 'practical' application where consequences are real. SMFs also help students develop critical thinking skills, help showcase the major for recruiting high-quality students; help create donor interaction; and help foster professional interaction. SMFs also help students secure additional internship and employment opportunities and enhance presentation and communication skill set development. Switching to performance objectives, growing the endowment is primarily important to fund scholarships, student travel, production costs and faculty support."

\section{How to start a SMIF?}

Because a SMIF mimics a real-life investment organization, the establishment of a SMIF starts with a client (donor) that provides the monetary funds and essentially hires a SMIF to invest these funds under stipulated investment guidelines. In our case, the VT Foundation initially provided $\$ 250,000$ in October 2012 for a student organization housed in the Department of Agricultural and Applied Economics to invest in corn, soybeans, wheat, and livestock. ${ }^{2}$ The investment guidelines are established by a client and typically include a benchmark, acceptable investment instruments, and trading restrictions. ${ }^{3}$ At VT, the guidelines from the VT Foundation stipulated that Invesco DB Agriculture Fund (DBA) was used as a benchmark. Acceptable instruments included exchange-traded funds and notes (ETF/ETN), and trading restrictions limited our positions not to exceed 30\% deviations from benchmark allocations. The ETF/ETNs were used

\footnotetext{
${ }^{2}$ SMIF program funding varies greatly across universities with most portfolios ranging from $\$ 40,000$ to $\$ 10$ million (Mullen and Salvucci, 2019). However, we believe that commodity SMIFs can be started with as little as $\$ 10,000$ because of the small size of ETF/ETN shares.

${ }^{3}$ Horstmeyer (2019) describes how investment guidelines, bylaws, and oversight committees can help minimize the risks of having students manage SMIF portfolios.
} 
instead of futures and options in order to avoid margin requirements and differences in regulation between securities and futures contracts.

The original SMIF consisted of four students and two faculty advisors and was named Commodity Investing by Students (COINS). By 2019, COINS grew to 30-40 students and two faculty advisors, our portfolio grew to $\$ 750,000$, our benchmark changed to the Bloomberg Commodity Index (Bloomberg, 2019), and the acceptable instruments included options on futures in addition to ETF/ETNs. ${ }^{4}$ The payment for our SMIF's services consists of a quarterly management fee computed based on the industry average percentage rate and the size of the portfolio, which is deducted from the portfolio balance every quarter. Management fees are used to support educational and social activities, as well as professional development experiences for SMIF members.

Our experience appears fairly typical for SMIFs around the country. Holzhauer et al. (2019) and Mullen and Salvucci (2019) explain that most SMIFs are funded by private donations or through university endowments. Some of the biggest challenges of creating a SMIF are associated with dealing with red tape and establishing the structure of the program including investment guidelines and organizational bylaws. Holzhauer et al. (2019) suggests that this process typically takes about a year. Another challenge described in the previous studies is access to a limited number of qualified students who are interested in participating in a SMIF (DeBoeuf, 2019). Typically, this challenge is resolved by opening access to students from various majors, as was the case with COINS. All studies agree that "successful formation and continuation of a SMIF needs a faculty champion. The faculty director has to encourage formation and active participation by students, has to play an oversight role to ensure that analysts and managers are performing their duties diligently, has to lobby for resources and manage them, has to establish and maintain industry contacts and has to provide continuity in transition periods. It is an extremely time consuming but rewarding commitment" (Holzhauer et al., 2019, p. 8). It is important that university administration recognizes the time and effort involved in running such a program and rewards the faculty member formally or informally (Holzhauer et al., 2019).

\section{SMIF's organizational structure}

As our SMIF grew over time to include more students and manage more commodities, its organizational structure was adjusted to accommodate these activities. Based on the composition of our benchmark, which includes 17 different commodities, our organization is split into three divisions: agriculture, energy, and metals. Organizational leadership consists of the heads of each division, the chief executive officer (CEO), the chief financial officer (CFO), the graduate fellow, and both faculty advisors, which comprise an executive committee, as shown in Figure 1 . The roles and responsibilities associated with each position are described in the group's policies and procedures document, which sets appropriate expectations and holds members accountable for their functions.

The CEO is responsible for overall group organization and development, implementation of weekly meetings, and communication with the client or external organizations. The CFO communicates approved trading orders to faculty advisors and ensures that portfolio returns are calculated correctly and accurately reported to the client. To ensure a smooth transition and continuity of the SMIF's operations, the CEO and CFO are elected by all student members for a calendar year term. Division heads are elected by division members for a one semester term, which may be repeated up to three times. The main function of the division heads is to coordinate activities within their division and provide a link between the executive committee and commodity analysts. As senior members of the organization, they are tasked with supporting

\footnotetext{
${ }^{4} \mathrm{We}$ had to switch to a different broker to gain access to commodity option trading.
} 


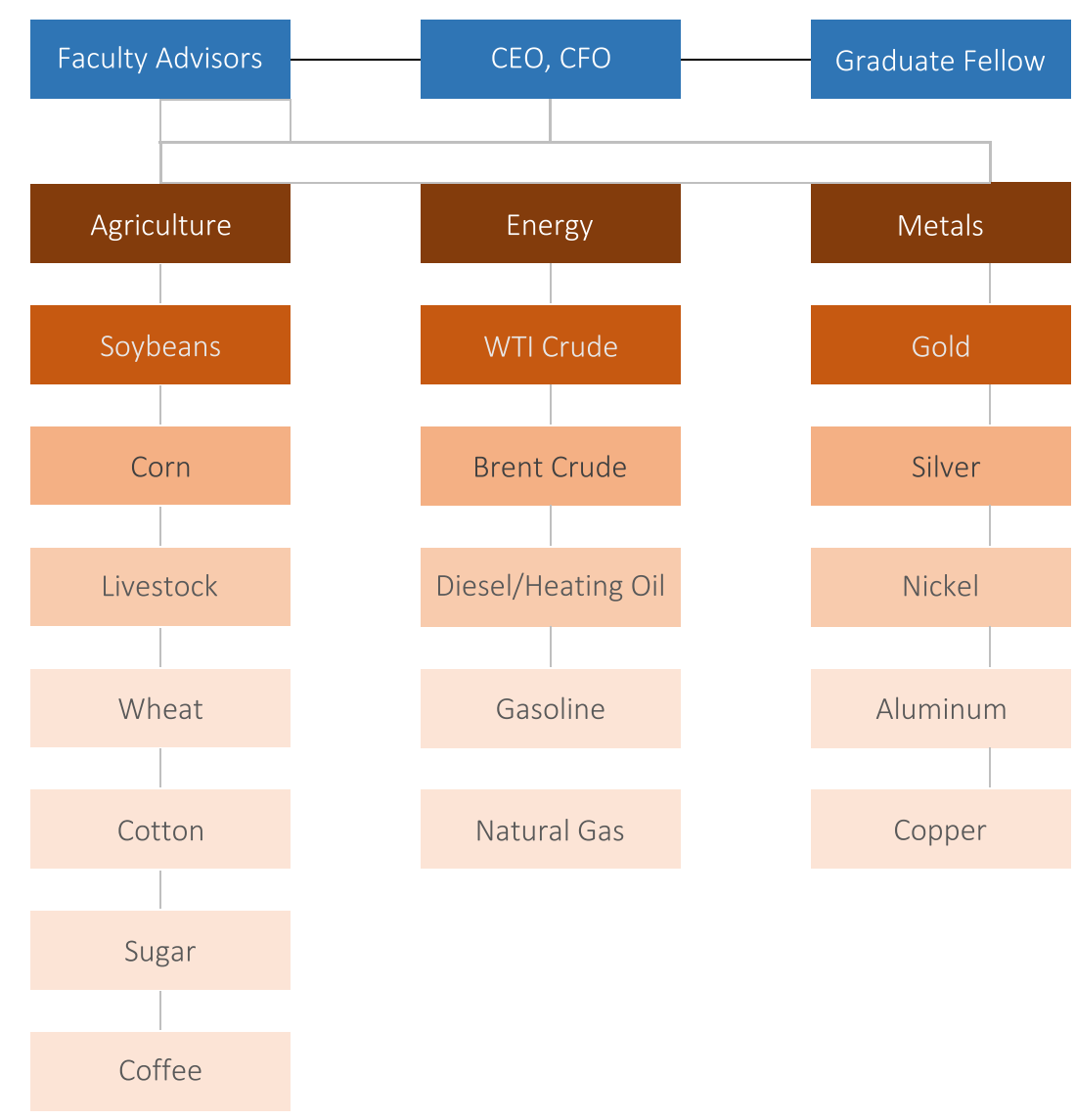

Figure 1. COINS (Commodity Investing by Students) organizational chart. Note: WTI, West Texas Intermediate.

the development of their analysts in terms of knowledge of commodity markets and the ability to clearly communicate market analyses.

A graduate fellow is appointed by a senior faculty advisor to provide research and teaching support for the SMIF. As a funded graduate student, the graduate fellow serves as a teaching assistant for two courses required for SMIF members (commodity futures and options and price analysis), conducts research related to commodity prices, and examines trading strategies that the group can implement, as well as assists in preparing proposals and reports for the VT Foundation. Although this role is not required, it is designed to help reduce the load on faculty involvement and is filled based on the availability of external funding and an acceptable candidate. Furthermore, additional leadership positions are created to address relevant needs of the SMIF as they arise and currently include professional development chair, social event chair, alumni relationship chair, recruitment chair, and website and social media chair. These positions are usually filled on an ad hoc basis by volunteers solicited by the CEO.

The SMIF is supported by two faculty advisors. The first faculty advisor serves as a portfolio manager, places the approved trades, and provides account statements and quarterly management fee invoices to the client. Students do not have direct access to the brokerage account but are provided with all necessary information by the portfolio manager. It is important to ensure that the SMIF is structured such that legal and fiduciary risk is minimized in-line with recommendations found in Gradisher et al. (2016). The second (senior) faculty advisor provides a leadership role and is responsible for various organizational issues that include operations, recruitment, 
training, research, and professional development topics. These topics are typically discussed during weekly meetings of the executive committee. However, it should be emphasized that although the ultimate authority rests with the faculty advisors, the student members of the executive committee provide day-to-day leadership for the group. The SMIF is organized as a studentled program, and its ability to self-monitor is usually strong enough that outside intervention by the faculty is a rare occurrence. This leadership experience is one of the main benefits of the SMIF and distinguishes it from normal classroom interactions or simulation approaches to experiential learning.

\section{SMIF's activities and operations}

The operations of a SMIF include the following functions: (1) recruitment, (2) training, (3) trading, and (4) interaction with client and alumni. Although trading is likely the primary function, a thorough implementation of all of the functions is necessary for the success of a SMIF. This section provides a detailed description of each of these functions.

\subsection{Recruitment}

Recruitment is vital for any student organization as it insures high quality of incoming members, as well as sustainability and growth of the program. Our recruitment effort is conducted once a year in the fall semester under the leadership of the recruitment chair. At the beginning of the recruitment process (early September), our members make presentations in classes across campus and at various campus events encouraging students to apply by filling out an electronic application form. One of the main differences between our commodity SMIF and traditional SMIFs that invest in stocks and bonds is that we recruit students from a variety of backgrounds whereas traditional SMIFs focus on finance majors. For example, out of 33 active members enrolled during spring 2019, 8 majored in agricultural economics, 11 in finance, 6 in business information systems, 2 in chemical engineering, 1 in computational modeling and data analytics/economics, 1 in biosystems engineering, 1 in computer science, 1 in electrical engineering/physics, 1 in neuroscience, and 1 in water resources. The strategy to recruit across majors was initially motivated by the desire to increase the size of the talent pool as the program grew, similar to the approach described by DeBoeuf (2019). This strategy has been followed during the last 5 years. ${ }^{5}$ Although this approach has added some challenges with new member training, it has been beneficial for the group as our members have been able to bring relevant discipline-specific knowledge to the group and expand the use of programming, data mining, and computational modeling, among other tools, in trade and market analysis through advanced training seminars as described in the next section.

Although our program does not have prerequisites, a minimum GPA of 3.0 is required as well as compulsory training upon admittance. New member applications are reviewed by the recruitment chair and member volunteers, and interviews are scheduled for qualified applicants. We typically receive between 60 and 90 applications and offer interviews to about 35-50 applicants. As the reputation of our program grows, so does the quality of applicants. The interviews consist of a market analysis presentation and additional behavioral questions and are conducted by current group members. This selection process ensures that we admit highly motivated individuals who are willing and able to learn and prepared to work hard and collaborate with the rest of the team. The results of the interview process are discussed in the executive committee meeting, and acceptance decisions are made by the executive committee and recruitment chair in late October. Faculty advisors do not participate in the interview process but help make acceptance decisions during the executive committee deliberations. These acceptance offers are conditional on successful completion of the new member training program.

\footnotetext{
${ }^{5}$ Prior to that, our recruitment efforts focused on agricultural economics and finance majors.
} 
Participation in the recruitment process gives our members a unique opportunity to take part in the interview process from the side of the recruiter. By going through this process, they get a better understanding of what recruiters are looking for, how candidates are evaluated, how resume information may come across in the interview process, and how to conduct themselves in the interview process. This experience prepares them for more efficient participation in their own interview processes upon graduation and improves their job-seeking skills.

\subsection{Training}

\subsubsection{New member training}

Because new members come from a variety of backgrounds and often do not possess any training in economics or finance, a rigorous training program is critical for their success as commodity analysts. New member training, conducted by current SMIF members, starts in early November shortly after admittance offers are extended. The topics for new member training include the basics of futures/options/ETFs/ETNs; types of market orders available through our broker; technical analysis; fundamental analysis for agriculture, energy, and metal markets; macroeconomic factors and their implications for commodity markets; and the group's policies and procedures. This information is summarized in the junior analyst handbook that is provided to each new member. Upon completion of this training, the executive committee administers an entrance exam. ${ }^{6}$ Students who have successfully passed the entrance exam become junior commodity analysts of COINS. They are assigned to a specific commodity based on their personal interests and the current needs of the group. Every junior analyst is paired with a senior analyst mentor for their first semester with COINS. These mentors help junior members analyze and propose new trades and are ultimately responsible for these trades.

Participation in new member training provides current COINS members with teaching and mentoring experience. This experience helps them solidify their own knowledge of market information as they must explain it to the new members and be able to answer questions that arise in the process. It also helps build relationships between current and new members to ensure that new members are comfortable in reaching out to their peers if they have any questions or problems. The mentoring relationships take it a step further and are designed to foster discussion of commodity markets regardless of whether there are any questions. We have observed that the success of mentoring relationships is strongly dependent on the personalities of the students involved and that extroverted pairs are more engaged and active than those who are introverted. To address these issues, we have tried to encourage students working on related commodities to have common discussions, which increases the size of their subgroups and reduces the impact of single personalities.

\subsubsection{Formal training}

In addition to new member training, COINS members are required to take a regular college class during their first year of participation in the program. This course helps them understand commodity markets on a deeper level. To provide flexibility and help members fit this requirement into their schedules, they have the choice of enrolling in classes in agricultural futures and options, price analysis, or commodity portfolio management to satisfy this requirement. We believe that this requirement adds rigor and structure to the training program for our SMIF. The students running for leadership positions within COINS have to pass one of these classes with a grade of $\mathrm{B}$ or higher. The 3.0 overall GPA requirement is monitored for all members every semester,

\footnotetext{
${ }^{6} \mathrm{New}$ member training is an important first step when new members are first exposed to the rigor of the program. During this process, some of the students realize that the requirements of the program may be too much for them to handle for various reasons. Usually we lose one to two new members in this process who decide not to continue with the program and end up not taking the entrance exam.
} 
and students who fall behind are put on probation. ${ }^{7}$ This requirement provides a reverse incentive for students to do better in their academic classes in order to continue their participation in COINS.

\subsubsection{Advanced training and professional development}

COINS members are also required to participate in weekly advanced training seminars where they have the opportunity to discuss specific topics of interest, meet with industry professionals, or share valuable skills. For example, in the spring of 2018 we welcomed visitors from Pinnacle Foods, Citibank, Smithfield Foods, Federal Reserve Bank of Richmond, and a private commodity trading company. We have also met with senior officials from the Intercontinental Exchange and Teucrium Funds using teleconferencing software. In addition, some of our members attended the U.S. Department of Agriculture's Agricultural Outlook Forum; the Governor's Conference on Agricultural Trade; and the NCCC-134 Conference on Applied Commodity Price Analysis, Forecasting, and Market Risk Management. Senior student members conducted Bloomberg terminal training, and our graduate fellow presented his thesis paper. The schedule for advanced training seminars varies every semester. It is discussed and determined by the executive committee to address the needs and interests of current members. The senior faculty advisor is responsible for organizing most of these seminars and trips. Most of the funds from the management fees that we earn are used to support these activities.

Participation in these seminars provides our members an opportunity to interact with successful industry professionals and learn from them both professionally and personally. These interactions clearly demonstrate professional opportunities for individuals interested in commodity markets and frequently result in internship and full-time job opportunities for our members. In addition to these seminars, our professional development chair helps all members format their resumes, shares tips on job searching and interviewing, and disseminates information about any ongoing recruitment events on campus. Over time, we have also developed an alumni network that shares employment opportunities with our members. The professional development support system that we have in place at VT results in about $80 \%$ internship placement and $100 \%$ job placement for our members.

\subsection{Trading}

The main goal of our SMIF is to provide positive risk-adjusted returns on investment for our client: the VT Foundation. Our returns are measured against a benchmark, which is currently the Bloomberg Commodity Index. The benchmark is passively managed with commodity weights updated annually. The goal of COINS is to beat the benchmark by actively managing the portfolio and continuously updating the commodity allocations by as much as $30 \%$ over or under the benchmark weights, based on investment guidelines. The portfolio is actively managed during the academic year from September through May, but it is matched back to the benchmark during the summer months when students are not on campus. Students may also have summer employment that prohibits them from engaging with the fund during this time. Fund performance is measured in terms of annualized relative returns.

Investing in commodities typically involves trading futures contracts. However, because trading futures is highly leveraged, it may create significant risk exposure for the investment portfolio. The availability of multiple contracts for a single commodity could also generate excessive burden for the portfolio manager. Additionally, trading of futures is regulated by a different agency than trading of securities (Commodity Futures Trading Commission rather than the Securities and

\footnotetext{
${ }^{7}$ The probation period usually lasts one semester; if by the end of the semester the problem is not fixed, the executive committee meets with the student and explains why his or her membership is terminated.
} 
Exchange Commission). In order to reduce potential risk exposure, eliminate the need for margin calls, and follow the same reporting requirements as other investment groups ${ }^{8}$ within VT, our client stipulated that ETFs and ETNs should be used as investment instruments rather than futures contracts.

ETFs (Poterba and Shoven, 2002) and ETNs (Wright, Diavatopoulos, and Felton, 2010) are relatively new types of traded securities that have grown in popularity over the past 20 years. In the case of an ETF, shares represent claims on an underlying pool of assets. For commodity ETFs, the asset pool is usually composed of the physical commodity or futures contracts. As an example, the Teucrium Corn Fund holds second to expire, third to expire, and December following third to expire corn futures contracts traded on the Chicago Board of Trade. ETNs are unsecured debt instruments issued by financial institutions. The price of the ETN tracks an index of futures contracts that is embedded in the ETN's indicative value. The indicative value or redemption value is the money owed by the issuer to investors holding the ETN. Because ETF/ETNs essentially represent the basket of futures contracts, students base their analysis on the fundamental factors that affect commodity futures markets. Therefore, proficiency in futures and options is not lost by moving to a more manageable derivative.

Trading decisions are made during weekly trading meetings that consist of (1) macroeconomic overview by the CEO, (2) trade proposals from each division, (3) tips from the professional development chair, and (4) organizational notices and updates. In the past, we requested market updates for all commodities, not just the ones with proposed trades. However, as our portfolio grew, this became infeasible as we tried to limit our trading meetings to 1.5 hours. In preparation for the general weekly trading meetings, each division holds its own meeting in which members discuss each commodity and potential trade activity.

A trade proposal for a position is prepared by the respective commodity analyst(s) and approved and forwarded by the division head to the CEO to be included in the weekly meeting. The analysts present their proposal to the group following a specific format that includes trade description (long or short) and size, type of order, and current and desired position relative to benchmark, accompanied by a rationale that consists of a combination of fundamental and technical analysis. This rationale is actively discussed in the meeting as we have emphasized the role of a devil's advocate in order to improve the quality of trades. The trade must be approved by a majority vote of participating members. Faculty advisors participate in the discussion but not the voting process. The approved trades are placed immediately after the meeting by one of the faculty advisors as the students do not have direct access to the brokerage account.

Sometimes markets cannot wait for weekly trading meetings. In these cases, a procedure is in place for an analyst to propose a trade that includes the same detail as required for the trading meeting. The analyst must explain the urgency of the trade and submit it electronically to the division head. If the urgency is justified, the trade must be approved electronically by the division head, CEO, CFO, and both faculty advisors before it is placed. These emergency trades are usually presented at the subsequent trading meeting so that all members are aware of this activity.

As we observed and evaluated our trading activities over time, we noticed that our members were very efficient in opening new positions but could be sluggish in closing them, which could either erase previous profits or accumulate large losses if the market went in the opposite direction. Based on this experience, over the last year we started requiring that each proposed trade be accompanied by limit and stop orders that locked in potential profits and losses at the time the trade was placed. Even though it may be difficult to place these limits effectively, we believe that this rule is beneficial for our portfolio as it limits our risk exposure and provides members with additional learning opportunities.

\footnotetext{
${ }^{8}$ Other SMIFs on the VT campus include SEED, which focuses on investments in stocks and has a portfolio of $\$ 5$ million, and BASIS, which focuses on investments in bonds and also has a portfolio of $\$ 5$ million.
} 
It is difficult to overestimate the learning outcomes our members obtain from participating in real trading. In addition to developing technical expertise in commodity market analysis and investing, our members improve on a wide range of soft skills. We have had students that were very well trained and very well prepared but simply afraid to pull the trigger because real money was involved. In these cases, it is the role of the mentor and the division head to back up and encourage the trade in order to support the confidence of the analyst. Informal feedback from previous members indicates that the ability to make decisions, take risks, and defend their viewpoints were some of the most important outcomes of their participation in COINS. Defending their viewpoints involves development of strong presentation skills. Our members stand in front of their peers and faculty advisors several times a semester to present and defend their point of view regarding commodity markets as they propose new trades. Finding the right balance between an active discussion and a collegial and supportive environment is very important, ensuring these experiences are constructive and not intimidating for junior analysts.

We have found that social interaction outside required SMIF activities helps our members get to know each other and feel more confident during trade discussions. Our social chair organizes events that include golf tournaments, bowling competitions, dinners, and other engagements with current members and alumni. This social interaction also helps our members develop a network of friends that they turn to not just to discuss markets, but also to seek personal and professional advice and support. Although these networks are important for everyone, they may be particularly valuable for first-generation students that often do not have access to the same resources as traditional students.

\subsection{Interaction with client, supporters, and alumni}

COINS's interaction with its client - the VT Foundation - is conducted mostly through quarterly performance reports. The quarterly, semiannual, and annual performance reports cover the periods January 1-March 31, April 1-September 1, and January 1-December 31, respectively. The reports summarize the relative performance of the portfolio during the respective period and provide summaries for all trade decisions, discuss organizational updates, and describe job placements. The reports differ in length and the level of detail included, with the quarterly being the shortest report and the annual being the most detailed. The graduate fellow is responsible for compiling the report using the components submitted by COINS members. The CEO writes a cover letter that describes organizational updates and job and internship placements. The CFO calculates and presents various measures of portfolio performance. Division heads provide a description of general market trends and collect the summaries of each trade placed within a reporting period from their analysts. The $\mathrm{CEO}$, the graduate fellow, and the faculty advisors edit the report, and the senior faculty advisor submits the report to the VT Foundation. Participation in writing the report helps our members improve their writing skills, holds them accountable for the trades they placed, and teaches them the basics of performance reporting.

Additionally, when the executive committee decides that changes to the investment guidelines ${ }^{9}$ would benefit the SMIF, its members prepare and submit a proposal to the VT Foundation. In the past, such proposals included a request to approve certain futures options positions as an acceptable instrument and a request to change the benchmark in order to increase commodity exposure by including metals in the portfolio. These proposals are reviewed by the VT Foundation and must be approved by the VT Foundation's Board of Directors, the same as any other changes to the VT Foundation's investment guidelines. Participation in preparing these proposals is limited to the executive committee, but it provides our student leaders another opportunity to improve their

\footnotetext{
${ }^{9}$ All changes to investment guidelines or organizational bylaws have to be discussed and approved by the general membership.
} 
writing, presentation, and persuasion skills and gives them a chance to make an impact on the future of the program.

As our program grew, we realized the importance of interaction with our alumni. Over 6 years of the program's existence, we developed a network of about 50 alumni that have become successful industry professionals. Most of our alumni give credit to their participation in COINS as an important component of their professional success and are passionate about the program. About a year ago, we started releasing monthly alumni newsletters that update our alumni about current developments in the program including market updates, jobs and internship placements, and advanced training seminars and activities. In these newsletters, we also invite our alumni to visit with our current members when they are back on campus. This initiative resulted in several visits and multiple updates on job opportunities from our alumni. These newsletters are also sent to our main supporters, the graduates of the Department of Agricultural and Applied Economics who initially came up with the idea of creating a commodity-focused SMIF at VT and saw it through to its implementation, supporting us every step of the way, both intellectually and financially.

\section{SMIF benefits and costs}

COINS members receive academic credit for their participation in the program by enrolling in the COINS class. This class is offered on a pass/fail basis every semester for two credit hours and may be repeated with different contexts for up to eight total hours (four semesters). This class is limited to COINS members and formalizes the group's activities and facilitates communication. Evaluation is based on successful compliance with member roles and responsibilities, with failure in compliance resulting in a failing grade. Several steps are described in policies and procedures to prevent the failure, including feedback from the division head and the CEO, as well as a probationary period.

However, the biggest advantage our SMIF provides for participating students is giving them access to real-life commodity investment experience, which is highlighted on their resumes. This tends to generate a lot of interest from the hiring companies as very few fresh college graduates have access to such experience. Some investment banks even go as far as to limit campus job interviews to SMIF participants only. Ultimately, the quality of job placements is the strongest evidence of SMIF impact. Many of our members accept full-time offers as early as a year before graduation. Our graduates have secured positions with Cargill, Smithfield Foods, General Mills, Kraft, Conagra, KPMG, Ernst and Young, Citi Bank, Bank of America, Wells Fargo, Deloitte Consulting, SunTrust Bank, Merrill Lynch, Capital One, Exxon, Fannie Mae, Intl FCStone, JBS, BJ's Wholesalers, and Pinnacle Foods, among other companies.

Informal feedback from our graduates rates their participation in COINS as some of the most valuable college experiences they have had, highlighting analytical and soft skill development as the main outcomes. "Being a member of COINS opened the door for a multitude of opportunities not seen by many during their college experience" describes one former student. "The analytical and soft skills I developed while being in the group allowed me to easily stand out from others applying for the same positions. My bosses and colleagues were impressed by my ability to present to a group, work well with a team, lead others, and analyze situations that had no easily solvable solutions. All these skills were developed in COINS where I analyzed commodity markets/data, formed an educated opinion on that data, and defended my convictions in front of my peers who asked tough questions to make sure the trade was well thought out ... I can easily say that without COINS, I would not have been competitive in any of the positions I applied for."

Another graduate reflects: "After several months in the workforce, I realize that COINS' collaborative, goal-driven, and team-oriented structure simulated a professional work environment more closely than any other collegiate organization in which I participated while at Virginia Tech. 
Beyond teaching students highly-technical subject matter relating to commodity trading and risk management, COINS' mission and framework encourages students to hone their leadership and soft skills. At regular meetings and professional networking events, student analysts are challenged with delivering multi-media presentations, conducting performance assessments, setting and refining goals, and delivering and receiving feedback. First developed during my years as a COINS analyst, this toolkit of soft skills has been invaluable to me throughout my transition into a professional career."

Networking and mentorship is consistently highlighted as another important outcome: "During my time in the group, several COINS senior analysts developed and presented a professional development curriculum to younger members based on their own interview and internship experiences. I benefitted enormously from the in-depth personal and professional development training that I received from COINS' rotating cast of professional guest speakers and from older students in the group. Despite the academic diversity across the club's members, cross-cohort mentorship is an important tenet of the club's culture that produces lasting friendships and professional connections between members. After nearly five months on the job, I have remained in touch with several other COINS alumni, who are important supporters and friends, based on our shared interests and mutual professional connections."

Leadership skills are also often listed as one of the main benefits of COINS: "Along with technical and soft skills, COINS ultimately taught me how to be a leader. Taking on leadership roles with real implications is a great responsibility to have prior to starting a professional career. It helps to build a foundation of accountability because the actions of the group have legitimate financial consequences." "COINS played a significant role in landing my job after graduation, and provided an unparalleled experience regardless of major or post-graduation plans. I think one of the greatest lessons investing has to offer is that it requires you to search for the truth. You have to be a contrarian, and stand up for what you believe the data is [sic] showing, regardless of what anyone else has to say. This is almost the definition of leadership. ... COINS teaches students to stand up boldly for what they believe, face the critique of others, and ultimately work together to find the truth and the best course of action. Because of my experience in COINS, I can confidently run a meeting with a diverse group and find the best course of action. The fact we're discussing technology instead of financial markets carries no weight."

It is clear from the description of COINS activities presented earlier in this article that students dedicate a lot of time and effort to their participation in the program. Each week, they spend about 1 hour in division meetings, $1-1.5$ hours in a trading meeting, and 1 hour in a training seminar. In addition to the structured requirements, they spend time daily analyzing commodity markets. Members of the executive committee also meet weekly for up to 1 hour to discuss program operations and initiatives. Volunteering for various COINS functions and activities takes yet additional time and effort. In other words, it is a huge commitment. We try to communicate this very clearly to the new members when they apply, resulting in a retention rate of more than $90 \%$ during their first semester of participation. Members that get through their first semester participate in COINS for about 2 years on average. However, the amount of interest, the number and the quality of applications that we receive each year, suggests that the students consider this significant investment of their time very valuable.

COINS incurs costs in terms of faculty time and effort as well. The faculty advisor responsible for portfolio management is required to participate in trading meetings and place trades and send monthly statements and quarterly invoices to the foundation. These activities likely take about 2 hours weekly. The senior faculty advisor participates in executive committee meetings and trading meetings and organizes and participates in training seminars. These activities take from 3 to 5 hours weekly during both fall and spring semesters. Thus, the costs in terms of faculty time are not trivial. Most previous studies recognize these high costs of faculty engagement but still emphasize creating a SMIF as a worthwhile undertaking (Mullen and Salvucci, 2019). 
The main benefits to faculty consist of access to some of the best students on campus that can be recruited to participate in a graduate program as COINS fellows or engaged to contribute to faculty research and outreach activities in commodity marketing and risk analysis. Furthermore, interaction with agribusiness companies through advanced training and professional development seminars has resulted in several funded projects that involved COINS students.

\section{Conclusions}

This article outlines the steps necessary for organizing and operating a SMIF focused on commodities. We suggest the student-managed commodity investment fund as a new frontier in commodity-focused experiential learning. A common misconception is that experiential learning is simply the act of doing something that is done in the real world; that to learn, the student must simply mimic the actions of others. As Kolb and Fry (1975) note in their seminal text on experiential learning, the concrete experience (doing) is only one aspect of the experiential learning model. Other parts of the process are observation and reflection, formation of abstract concepts, and testing of concepts in new situations. These components are equally important in achieving the ultimate goal of learning (Kolb, 2014). The commodity-focused SMIF described in this article provides a holistic approach to the experiential learning model that may be reproduced at other institutions.

The main advantages of this model are its holistic approach, relevant experience, and comprehensiveness. By closely mimicking a real-life investment organization, students are exposed to all aspects of its operations including market analysis and investment decisions; client relationships and reporting; recruitment, training, and human capital management; networking; and professional development, to name a few. Students often view this experience as similar to that of running a start-up, which proves very valuable and relevant for their future careers.

Another important characteristic of a SMIF, which may be viewed as both a benefit and a drawback of this approach, is its relative exclusiveness. Although no prior knowledge of commodity markets is required to join the organization, new members are selected based on their passion, dedication, and desire and ability to learn. Successful participation in a SMIF is a challenging and demanding experience that differentiates students from their peers when entering the job market. Therefore, the main drawback of a SMIF is that it is not suitable for all students. Students that are not interested in commodity markets and are not prepared to work hard will not benefit from pursuing this opportunity.

One of the innovations associated with our commodity-focused SMIF, which differentiates it from traditional SMIFs developed in business schools, is its integration with all aspects of the landgrant mission including teaching, research, and extension. The teaching component is reflected in various levels of training provided to SMIF members, including student lead training, faculty and industry lead seminars, and traditional lecture-based courses. The graduate fellow provides a link between undergraduate members, operation of the fund, and the research output. Furthermore, because our members are proficient in the latest market news, they are well positioned to support faculty outreach activities in commodity marketing. Taken together, these aspects of the commodity SMIF suggest a bold new approach to student involvement in land-grant activities.

SMIFs provide an effective experiential learning avenue that gives students real-life commodity market investment experience, market analysis and presentation skills, and long-term contacts and networks with fellow members and industry professionals. Thus far, our assessment of outcomes from participation in a SMIF has been based on our personal observations and anecdotal evidence. Finding ways to measure, quantify, and analyze these outcomes are primary goals for future research on this topic. 
Financial support. This research received no specific grant from any funding agency or commercial or not-for-profit sectors.

Conflict of interest. None.

\section{References}

Bessler, W., and D. Wolf. "Do Commodities Add Value in Multi-asset Portfolios? An Out-of-Sample Analysis for Different Investment Strategies.” Journal of Banking \& Finance 60(November 2015):1-20.

Bloomberg. "Bloomberg Commodity Index." 2019. Internet site: https://www.bloomberg.com/quote/BCOM:IND (Accessed March 12, 2019).

Gradisher, S., D.R. Kahl, J.M. Clinebell, and J.L. Stevens. "Fiduciary and Legal Considerations for Student-Managed Investment Funds." Journal of Education for Business 91, 2(2016):83-89.

Holzhauer, H.M., T.A. Krause, J. Russell, D. Harrell, and A. Bandopadhyaya. "Student Managed Funds - A Panel Discussion." Managerial Finance (2019). doi:10.1108/MF-08-2018-0406.

Horstmeyer, D. "Formation of a Student Managed Investment Fund: Risk Management and Oversight." Managerial Finance (2019). doi:10.1108/MF-08-2018-0396.

Kliethermes, B.J., J.L. Parcell, and J.R.V. Franken. "What to Teach Future Commodity Merchandisers: A Survey of Skills and Needs." NACTA Journal 55, 3(2011):19-27.

Kolb, D.A. Experiential Learning: Experience as the Source of Learning and Development. Upper Saddle River, NJ: Pearson, 2014.

Kolb, D.A., and R.E. Fry. “Toward an Applied Theory of Experiential Learning.” Theories of Group Process. C. Cooper, ed. London: John Wiley, 1975, pp. 33-56.

Koontz, S.R., D.S. Peel, J.N. Trapp, and C.E. Ward. “Augmenting Agricultural Economics and Agribusiness Education with Experiential Learning.” Review of Agricultural Economics 17, 3(1995):267-74.

Lawrence, E.C. "Learning Portfolio Management by Experience: University Student Investment Funds." Financial Review 25, 1(1990):165-73.

Lawrence, E.C. "Financial Innovation: The Case of Student Investment Funds at United States Universities." Financial Practice and Education 4, 1(1994):47-53.

Lawrence, E.C. “Student Managed Investment Funds: An International Perspective." Journal of Applied Finance 18, 2(2008): $1-17$.

Mullen, M.G., and D. Salvucci. “A Five-Year Retrospective on an Undergraduate SMIF Program.” Managerial Finance 45, 5(2019):622-36.

Parcell, J.L., and J.R. Franken. "Teaching Options and Futures Trading through Experiential Learning." NACTA Journal 53, 3(2009):11-16.

Peng, Z.J., W.P. Dukes, and R. Bremer. "Evidence on Student-Managed Funds: A Survey of U.S. Universities." Business Education \& Accreditation 1, 1(2009):55-64.

Poterba, J.M., and J.B. Shoven. "Exchange-Traded Funds: A New Investment Option for Taxable Investors." American Economic Review 92, 2(2002):422-27.

Tierney, W.I., Jr. "Students Form Commodity Pool to Learn about the Futures Market." Applied Economics Perspectives and Policy 11, 2(1989):289-96.

Wright, C., D. Diavatopoulos, and J. Felton. "Exchange-Traded Notes: An Introduction." Journal of Investing 19, 2(2010):27-37.

Cite this article: Massa OI and Ramsey AF (2020). Student-Managed Commodity Fund-A New Frontier in Experiential Learning. Journal of Agricultural and Applied Economics 52, 64-77. https://doi.org/10.1017/aae.2019.33 